\title{
STUDY ON THE MECHANICAL PROPERTIES AND FRACTURE BEHAVIOR OF CHOPPED STEEL FIBER REINFORCED SELF COMPACTING CONCRETE
}

\author{
Biswajit Jena ${ }^{1}$, Bipin Bihari Mohanty ${ }^{2}$ \\ ${ }^{1}$ Assistant Professor, Department of Civil Engineering, DRIEMS Cuttack-754022, India \\ ${ }^{2}$ Professor, Department of Civil Engineering, DRIEMS Cuttack-754022, India
}

\begin{abstract}
Fiber reinforced concrete (FRC) is widely practiced with high ductility and sufficient durability. In this study, the properties of the volume fraction and length of steelfiber $(S F)$ on the mechanical properties of FRC were analyzed. This paper provides result data of the compressive strength, and split tensile strength, flexural strength of steel fiber reinforced concrete. The variables in this study the percentage of volume fraction $(0,1.0,1.5,2,2.5 \& 3)$ of steel fibersby weight of total weight of concrete. For compression test, a result data obtained has been analyzed and related with a control specimen ( $0 \%$ fiber). A relationship between Compressive strength vs. fiber volume fraction and tensile strength vs. fiber volume fraction \& flexural strength vs. fiber volume fraction of steel fiber are represented graphically. The addition of fiber enhanced the ductility significantly. Result data clearly shows a small increase in compressive strength for M30 Grade of concrete due to addition of $0.1 \%$ steel fiber, but for $0.2 \%$ addition a marginally increase in strength after that the strength is decreased.
\end{abstract}

Key words: self-compacting concrete, steel fiber, mechanical properties, volume fraction, fracture energy

\section{INTRODUCTION:}

It is a concrete which is consideredtoplaced and compacted every part of the corner of the formwork, even in the presence of dense reinforcement, purely by means of own weight and less or no vibrational effort.However, various investigations are moving on in various characteristics of the mechanical behavior and structural applications of SCC.SCC has established to be effective material, so there is a need to guide further investigation on the normalization of self-consolidating characteristics and its behavior to apply on different structural construction, and its usage in all perilous and inaccessible project zones for superior quality control.Several studies have shown that fiber reinforced composites are more efficient than other types of composites. The keydetermination of the fiber is to restrict cracking and to increase the fracture toughness of the brittle matrix through bridging action in both micro and macro cracking of the matrix. At initial stage and the hardened state, Inclusion of fibers improves the properties of the concrete especially of the high performance concrete like SCC. Hence researchers have focused on study of the strength and durability aspects of fiber reinforced SCC. This mechanism growths the demand of energy for the crack to propagate. The linear elastic behavior of the matrix is not affected significantly for low volumetric fiber fractions.

The objective of present research is to mix design of SCC of grade M30 and to investigate the effect of inclusion of chopped steel fiber on fresh properties and hardened properties of SCC. The effects of the volume fraction and length of steel fiber (SF) on the mechanical properties of
FRC were analyzed. The outcomes indicate that adding SF significantly improves the tensile strength, flexural strength and toughness index, whereas the compressive strength shows no obvious gain. Furthermore, the length of SF presents an influence on the mechanical properties.Fresh properties comprise flow ability, passing ability, and viscosity related segregation resistance. Hardened properties to be studied are compressive strength, splitting tensile strength, flexural strength, and fracture test.

\section{EXPERIMENTAL PROGRAMME:}

\subsection{Materials}

Portland slag cement [1] of Konark brand available in the local market was used in the present studies. The coarse aggregate used were $20 \mathrm{~mm}$ and $10 \mathrm{~mm}$ down size. Natural river sand has been collected from Coal River, Rourkela, Orissa and conforming to the Zone-III as per IS-383-1970 [2].Fly ash is used. The SikaViscocrete Premier from Sika is super plasticizer and viscosity modifying admixture. Steel fiber of length $12 \mathrm{~mm}$ of $0 \%, 0.05 \%, 0.1 \%, 0.15 \%$, and $0.2 \%$ volume fraction by weight of the total weight of concrete was used in the investigations. 
Table-1: Mechanical properties of steel fiber

\begin{tabular}{|c|c|c|c|c|c|}
\hline Fiber variety & Length $(\mathbf{m m})$ & $\begin{array}{c}\text { Density } \\
\left(\mathbf{g} / \mathbf{c m}^{\mathbf{3}}\right)\end{array}$ & $\begin{array}{c}\text { Elastic } \\
\text { modulus(GPa) }\end{array}$ & $\begin{array}{c}\text { Tensile } \\
\text { strength(MPa) }\end{array}$ & $\begin{array}{c}\text { Elong. At } \\
\text { break }(\mathbf{\%})\end{array}$ \\
\hline $\mathrm{SF}$ & 20 & $0.91-0.95$ & $200-500$ & $500-200$ & $0.5-3.5$ \\
\hline
\end{tabular}

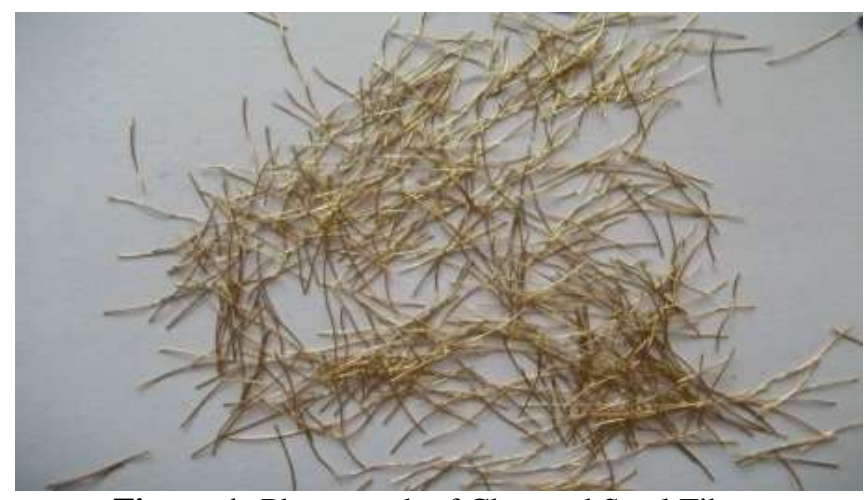

Figure-1: Photograph of Chopped Steel Fiber

\subsection{Experimental Procedures:}

The mixing of materials properly mixed in a power operated concrete mixer. Adding coarse aggregate, fine aggregates, cement and mixing it with fly ash properly mixed in the concrete mixer in a dry state for a few seconds. Then the water added and mixing it for three minutes. During this time the air entraining agent and the water reducer are also added. Dormant period was $5 \mathrm{mins}$. To obtain the steel fiber reinforced SCC, the requiredfiber percentage was added to the already prepared design mix, satisfying the fresh SCC requirements.

Calculation for M30 grade of SCC was done following EFNARC code 2005 in the mix design $15 \%$ of fly ash use as a replacement for cement to achieve the target strength. Viscocrete admixture was used to reduce the water content and improve workability as per the requirement for SCC.

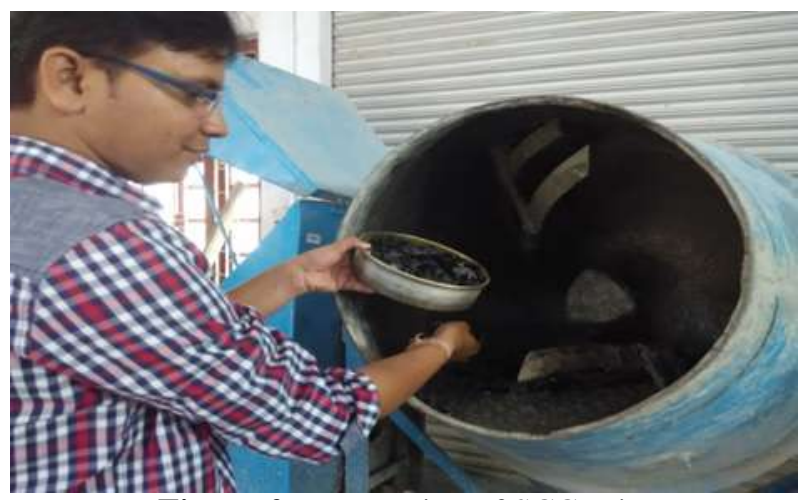

Figure-2: Preparation of SCC Mix

Table-2 Adopted Mix Proportions of SCC

\begin{tabular}{|c|c|c|c|c|c|}
\hline $\begin{array}{c}\text { Cement } \\
\left(\mathrm{kg} / \mathrm{m}^{3}\right)\end{array}$ & $\begin{array}{c}\text { Fly } \\
\text { Ash } \\
\left(\mathrm{kg} / \mathrm{m}^{3}\right)\end{array}$ & $\begin{array}{c}\text { Water } \\
\left(\mathrm{kg} / \mathrm{m}^{3}\right)\end{array}$ & $\begin{array}{c}\text { FA } \\
\left(\mathrm{kg} / \mathrm{m}^{3}\right)\end{array}$ & $\begin{array}{c}\mathrm{CA} \\
\left(\mathrm{kg} / \mathrm{m}^{3}\right)\end{array}$ & $\begin{array}{c}\mathrm{SP} \\
\left(\mathrm{kg} / \mathrm{m}^{3}\right)\end{array}$ \\
\hline 420.35 & 63.05 & 176.54 & 899.55 & 596.9 & 5.044 \\
\hline 1 & 0.15 & 0.42 & 2.14 & 1.42 & 0.012 \\
\hline
\end{tabular}

\subsection{Casting of Specimens}

Forty twonumber cubes $(150 \times 150 \times 150) \mathrm{mm}$, forty two numbers cylinders $(150 \times 300) \mathrm{mm} \&$ forty two numbers prisms $(100 \times 100 \times 500) \mathrm{mm}$ were cast and investigations were conducted to study the mechanical behavior, fracture behavior of steel fiber reinforced SCC (SFC).

\subsection{Tests on Fresh Concrete}

To determine the fresh properties of SCC, different methods were developed. Slump flow and V-Funnel tests have been proposed for testing the deformability and viscosity respectively. L-Box test have been proposed for determining the segregation resistance.
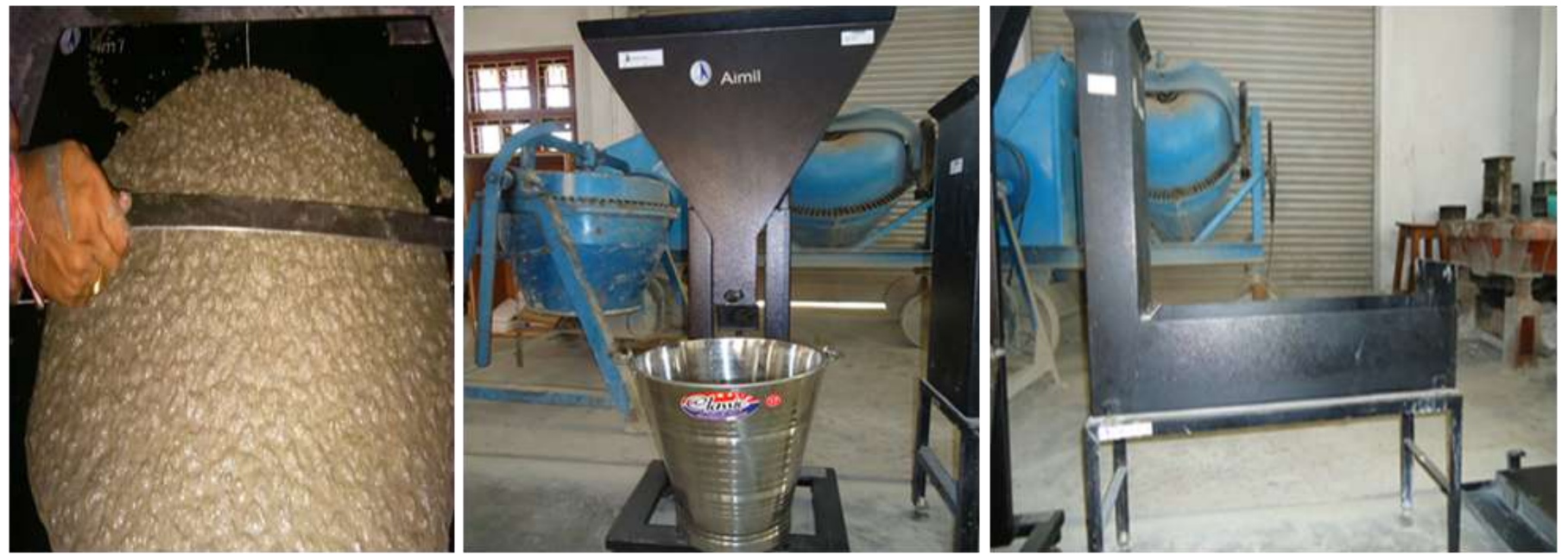

Figure-3: (A) Slump flow test, (B) V-Funnel test, (C) L-Box test 


\subsection{Testson Hardened Concrete}

A proper time schedule for testing of hardened SCC specimens was maintained in order to ensure proper testing on the due date. The specimens were tested using standard testing procedures as per IS: 516-1959.

\subsection{Fracture Test}

The ductility can be measured by fracture behavior of FRSCC and to determine fracture energy, prisms specimen of dimension $100 \mathrm{~mm} \times 100 \mathrm{~mm} \times 500 \mathrm{~mm}$ were cast with a notch of $5 \mathrm{~mm}$ width $(\mathrm{n} 0)$ and $30 \mathrm{~mm}$ depth as per the specification of the specimen. The schematic diagram of specimens and loading arrangement of test setup shown in the Fig.4 \& Fig.5.During testing, Crack Mouth Opening Displacement (CMOD) was noted using through two dial gauges as shown in fig5.



Figure-4: Schematic Diagram of Notched Specimen

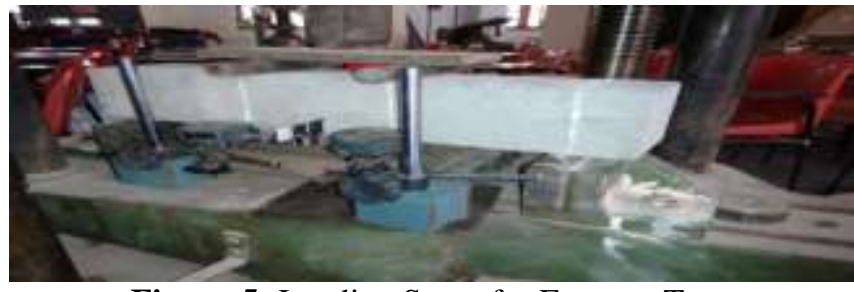

Figure-5: Loading Setup for Fracture Test

\section{RESULT \& DISCUSSION}

\subsection{Fresh Concrete Properties}

The Table-3indicatesa reduction of flow value owing to inclusion of fibers. The reason for this phenomenon is that a network structure may form due to the distributed fiber in the concrete, which restrains mixture from segregation and flow. The slump flow decreases with increase in fiber percentage. The T50 flow, which was measured in terms of time (seconds) increases as the slump flow value decreases. The decrease in slump value is due to the increase in the percentage of fiber. The L-Box value increases as the slump flow value increases. The increase in slump value is due to the increase in the percentage of fiber as well as the L-Box value also increases. The V-Funnel test \& T50 flow, which was measured in terms of time (seconds) \& both the value measured are dependent with each other. V-Funnel value and $\mathrm{T} 5$ flow increases as the slump flow value decreases. The decrease in slump value is due to the increase in the percentage of fiber.

Table-3: Fresh Concrete Results

\begin{tabular}{|c|c|c|c|c|c|c|}
\hline Sample & $\begin{array}{c}\text { Slump flow } \\
\mathbf{5 0 0 - 7 5 0 m m}\end{array}$ & $\begin{array}{c}\mathbf{T}_{\mathbf{5 0}} \text { flow } \\
\mathbf{2 - 5} \mathbf{s e c}\end{array}$ & $\begin{array}{c}\text { L-Box }\left(\mathbf{H}_{\mathbf{2}} / \mathbf{H}_{\mathbf{1}}\right) \\
\mathbf{0 . 8 - 1 . 0}\end{array}$ & $\begin{array}{c}\text { V-Funnel } \\
\mathbf{6 - 1 2 s e c}\end{array}$ & $\begin{array}{c}\text { T5 Flow } \\
\text { +3sec }\end{array}$ & Remarks \\
\hline PSC & 715 & 1.7 & 0.95 & 5 & 9 & Low viscosity (Result Satisfied) \\
\hline SFC-1 & 650 & 2.5 & 0.85 & 8 & 13 & Result Satisfied \\
\hline SFC-1.5 & 625 & 3.8 & 0.81 & 9 & 14 & Result Satisfied \\
\hline SFC-2 & 575 & 5.2 & 0.68 & 10 & 16 & High viscosity Blockage (RNS) \\
\hline SFC-2.5 & 515 & 6 & 0.59 & 11 & 18 & Too high viscosity Blockage (RNS) \\
\hline SFC-3 & 480 & 6 & 0.59 & 11 & 18 & Too high viscosity Blockage (RNS) \\
\hline
\end{tabular}

\subsection{Hardened Concrete Properties}

To compare the various mechanical properties of the FRSCC mixes the standard specimens were tested after 7 days and 28 days of curing. The results are summarized in Table 4 . The graph shows the optimum fiber content for maximum strength in mixes with different fibers.The highest 7-day compressive strength was observed for mix with $0.25 \%$ steel fiber and lowest for mix with $0.1 \%$ steel fiber.The highest 28-days compressive strength was observed for mix with $0.25 \%$ steel fiber and lowest for mix with $0.3 \%$ steel fiber.The highest 28 -days split tensile strength was observed for mix with $0.25 \%$ steel fiber and lowest for mix with $0.1 \%$ steel fiber.The highest 28 -days flexural strength was observed for mix with $0.2 \%$ steel fiber and lowest for mix with $0.1 \%$ steelfiber.
Table- 4: Hardened Concrete Properties of SCC and FRSCC

\begin{tabular}{|c|c|c|c|c|}
\hline Mixes & $\begin{array}{c}\text { 7-Day } \\
\text { compressive } \\
\text { strength } \\
\text { (MPa) }\end{array}$ & $\begin{array}{c}\text { 28-days } \\
\text { compressive } \\
\text { strength } \\
\text { (MPa) }\end{array}$ & $\begin{array}{c}\text { 28-days } \\
\text { split } \\
\text { tensile } \\
\text { strength } \\
\text { (MPa) }\end{array}$ & $\begin{array}{c}\text { 28-days } \\
\text { flexural } \\
\text { strength } \\
\text { (MPa) }\end{array}$ \\
\hline PSC & 42.85 & 48.22 & 3.42 & 12 \\
\hline SFC-1 & 49.35 & 54.72 & 3.54 & 13.22 \\
\hline SFC-1.5 & 50.22 & 60.35 & 3.80 & 14.25 \\
\hline SFC-2 & 50.22 & 66.13 & 4.23 & 17.22 \\
\hline SFC-2.5 & 52.75 & 70.44 & 4.56 & 15.5 \\
\hline SFC-3 & 50 & 53.33 & 3.93 & 13.33 \\
\hline
\end{tabular}




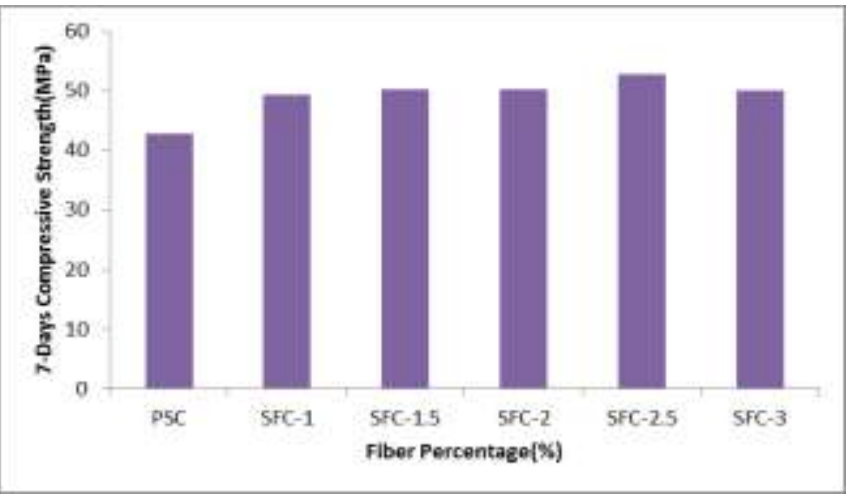

Figure-6: Variation of Compressive strength For Different SCC Mixes At 7days

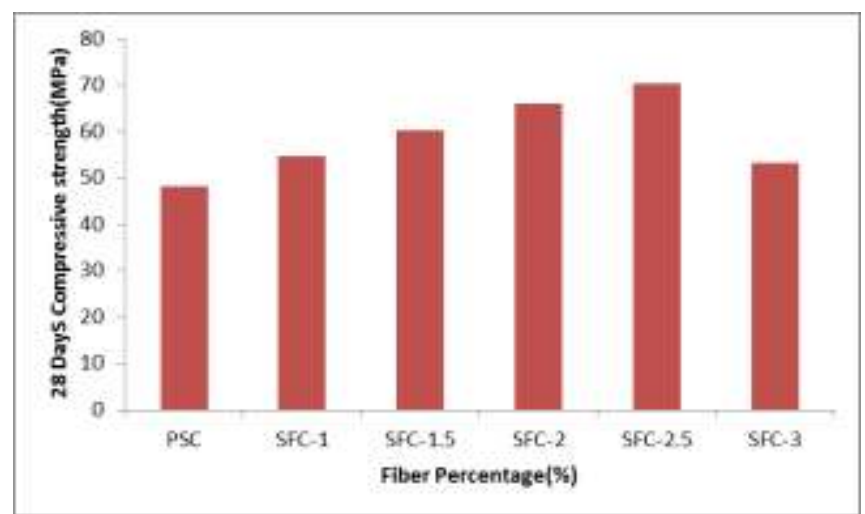

Figure-7: Variation of Compressive strength For Different SCC Mixes At 28days

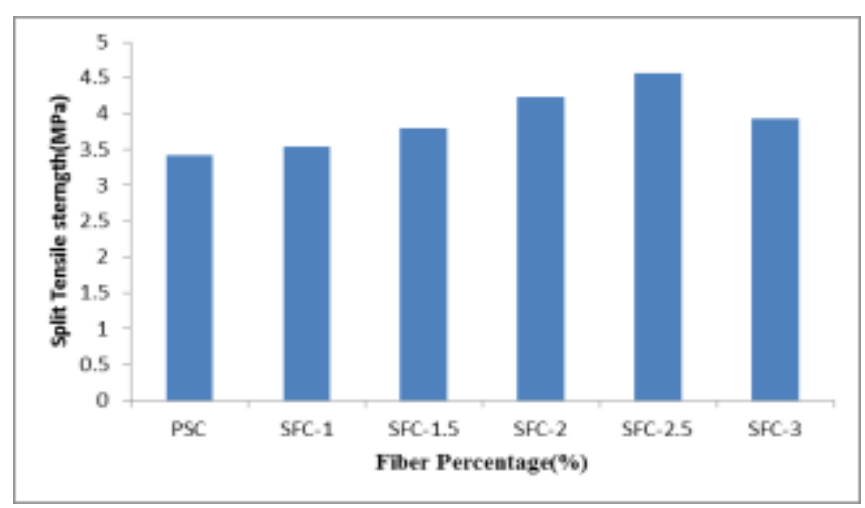

Figure-8: Variation of Split Tensile strength For Different SCC Mixes At 28days

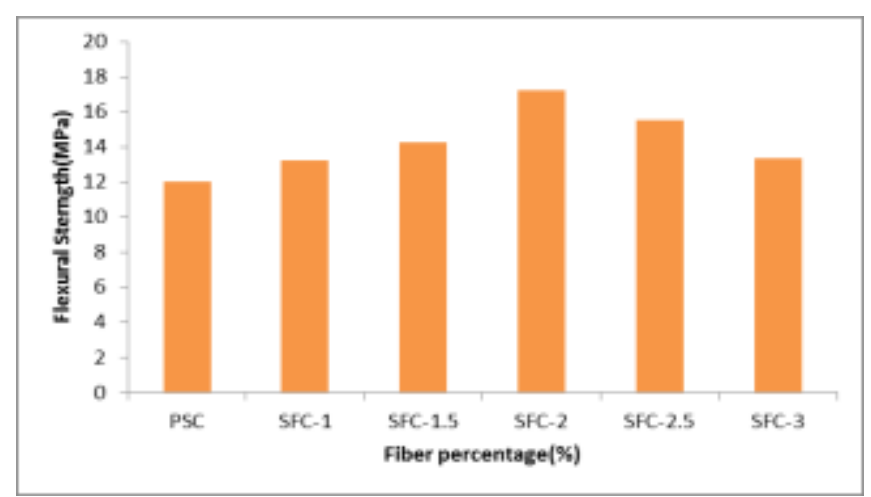

Figure-9: Variation of Flexural strength For Different SCC Mixes At 28days

\subsection{Fracture Test Results}

\section{Load-CMOD Behavior}

The load vs. Crack mouth opening deflection diagrams obtained clearly proved that the addition of fibers to SCC increase ductility whereas control beam PSC exhibited brittle behavior. In each series the mix which gave maximum compressive strength rendered maximum ductility. The area below the load deflection curve represents toughness. Almost same pattern of behavior was observed from all mixes.

The observations made during the tests (LOAD-CMOD) were used to draw the LOAD-CMOD curves. The ultimate load and the fracture parameters were determined.

From table $5 \&$ fig 10 it is observed that the fracture behavior of SFC is more than PSC in all fiber contents. As compared to PSC the increase in ultimate load for SFC was around $40.2 \%, 57.7 \%, 140.2 \%, 121.82 \%, 108.7 \%$ when adding $0.1 \%, 0.15 \%, 0.2 \%, 0.25 \%, 0.3 \%$ fibers respectively. As the fiber content increased, the fracture behaviors were also found to be increased for GFC

Table-5: LOAD-CMOD RESULT FOR SFC

\begin{tabular}{|c|c|c|c|c|c|c|}
\hline \multirow{2}{*}{$\begin{array}{c}\text { 雷 } \\
\text { 互 }\end{array}$} & \multicolumn{7}{|c|}{ CMOD(MM) } \\
\cline { 2 - 7 } & PSC & SFC-1 & SFC-1.5 & SFC-2 & SFC-2.5 & SFC-3 \\
\hline 0 & 0 & 0 & 0 & 0 & 0 & 0 \\
\hline 0.75 & 0 & 0 & 0.001 & 0 & 0 & 0 \\
\hline 1 & 0 & 0 & 0.002 & 0 & 0 & 0 \\
\hline 2 & 0.01 & 0.004 & 0.006 & 0 & 0 & 0 \\
\hline 3 & 0.08 & 0.006 & 0.008 & 0 & 0.02 & 0 \\
\hline 4 & 0.26 & 0.009 & 0.024 & 0 & 0.05 & 0.04 \\
\hline 4.25 & 0.28 & 0.01 & 0.033 & 0 & 0.06 & 0.05 \\
\hline 5 & & 0.16 & 0.05 & 0 & 0.08 & 0.09 \\
\hline 5.5 & & 0.2 & 0.11 & 0 & 0.09 & 0.13 \\
\hline 6 & & 0.41 & 0.18 & 0 & 0.13 & 0.16 \\
\hline 6.5 & & & 0.25 & 0.01 & 0.17 & 0.18 \\
\hline 6.75 & & & 0.3 & 0.03 & 0.18 & 0.19 \\
\hline 7 & & & & 0.03 & 0.21 & 0.22 \\
\hline 8 & & & & 0.06 & 0.32 & 0.35 \\
\hline 9 & & & & 0.13 & 0.46 & 0.51 \\
\hline 9.5 & & & & 0.18 & 0.5 & \\
\hline 10 & & & & 0.22 & & \\
\hline 10.25 & & & & 0.27 & & \\
\hline
\end{tabular}




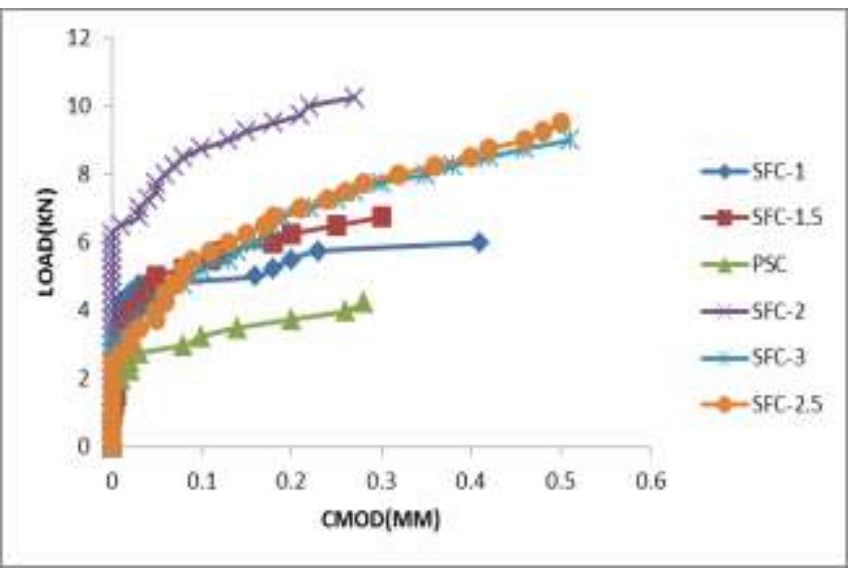

Figure-10: Load- CMOD curve for SCC mixes

\section{CONCLUSION}

- Addition of fibers to self-compacting concrete causes loss of basic characteristics of SCC measured in terms of slump flow, etc.

- Addition of fibers to self-compacting concrete improve mechanical properties like compressive strength ,split tensile strength, flexural strength etc. of the mix.

- There was an optimum percentage of each type of fiber, provided maximum improvement in mechanical properties of SCC.

- Mix having $0.15 \%$ steelfiber, $0.2 \%$ of steel fiber and $0.25 \%$ of steel fiber were observed to increase the mechanical properties to maximum.

- $0.2 \%$ addition of steel fiber to SCC was observed to increase the 7-days compressive strength by $23.9 \%, 28$ days compressive strength by $46 \%, \& 0.25 \%$ steel fiber increase the split tensile strength by $33.33 \%$, flexural strength by $43.5 \%$.

- The load vs. crack mouth opening displacement diagrams for FRSCC exhibited increase in fracture energy properties of the mixes. This is owing to crack arresting mechanism of the fibers in the matrix. In this regard the $0.2 \% \& 0.25 \%$ steel fiber exhibited best performance.

\section{ACKNOWLEDGMENT}

The experimental work was conducted at Structural Engineering lab of Civil Engineering Department of NIT, Rourkela. The work involved mixing, casting and testing of standard specimens.

\section{REFERENCES}

[1] IS 455:1989 Portland Slag Cement - Specification [2]IS 383:1970 Indian Standard specification for coarse and fine aggregates from natural sources for concrete

[3] IS650:1991 Indian Standard Standard sand for testing cement - Specification

[4] Nagamoto N., Ozawa K., Mixture properties of SelfCompacting, High-Performance Concrete, Proceedings, Third CANMET/ACI International Conferences on Design and Materials and Recent Advances in Concrete
Technology, SP-172, V. M. Malhotra, American Concrete Institute, Farmington Hills, Mich. 1997, p. 623- 637.

[5] K.H. Khayat, Z.G., Use of viscosity-modifying admixture to enhance stability of fluid concrete. ACI Mater. J. 94 1997: p. $332 \pm 341$

[6] Nan Sua, Kung-Chung Hsub, His-Wen Chaic, A simple mix design method for self-compacting concrete, Cement and Concrete Research 31 (2001) 1799-1807

[7] EFNARC: Specification and guidelines for selfcompacting concrete, February 2002.

[8] Okamura H., and Ouchi M., (2003), "Self-Compacting Concrete", Journal of advanced Concrete Technology, Vol.1, No. 1, pp.(5-15).

[9] IS 10262:2009 Recommended guidelines for concrete mix design .Bureau of Indian standards, New Delhi

[10] Wangjun et al.,'Experimental research on mechanical and working properties of non-dipping chopped basalt fiber reinforced concrete",3rd international conference on IMIMIE-2010

[11] Liberato Ferrara, Yon-Dong Park, Surendra P. Shah, A method for mix-design of fiber-reinforced selfcompacting concrete.

[12] Available from: http://www.selfconsolidatingconcrete.org.

[13] Dixon, R.G.N., Self compacting concrete, in Advance Concrete Technology.

[14] Chaohua Jiang, Ke Fan, Fei Wu, Da Chen, "Experimental study on the mechanical properties and microstructure of chopped basalt fibre reinforced concrete", Materials and Design 58 (2014) 187-193

[15] M.G. Alberti, A. Enfedaque, J.C. Gálvez, On the mechanical properties and fracture behavior of polyolefin fiber-reinforced self-compacting concrete, Construction and Building Materials 55 (2014) 274-288

[16] Nan Su ,Buquan Miao b, A new method for the mix design of medium strength flowing concrete with low cement content, Cement \& Concrete Composites 25 (2003) $215-222$

\section{BIOGRAPHIES}



Biswajit Jena is Assistant Professor, Department Of Civil Engineering, DRIEMS, Cuttack. He did his M.TECH in Structural Engineering from NIT Rourkela. He has more than 4 years of teaching \& industrial experience. $\mathrm{He}$ has published journal papers \& attended many conferences on concrete technology.Email-Id: biswa.tech88@gmail.com

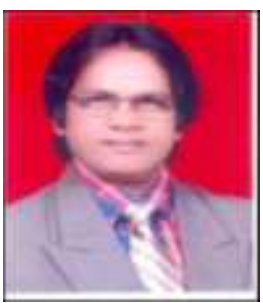

Bipin Bihari Mohanty is Professor, Deparment of Civil Engineering, DRIEMS, Cuttack. He did his ME from VSSUT Burla in the year of 1999. He has more than 25 years of teaching \& industrial experience.He has published journal papers \& attended many conferences on civil engineering. Email-

Id: bipinbihari2302@gmail.com 